\title{
IL-15 Mediates Mitochondrial Activity through a PPAR $\delta$-Dependent-PPAR $\alpha$-Independent Mechanism in Skeletal Muscle Cells
}

\author{
Shantaé M. Thornton, ${ }^{1}$ James E. Krolopp, ${ }^{1}$ and Marcia J. Abbott ${ }^{1,2}$ \\ ${ }^{1}$ Department of Health Science and Kinesiology, Crean College of Health and Behavioral Sciences, Chapman University, \\ Orange, CA, USA \\ ${ }^{2}$ Department of Biological Sciences, Human and Evolutionary Biology Section, Dana and David Dornsife College of Letters, \\ Arts and Sciences, University of Southern California, Los Angeles, CA, USA
}

Correspondence should be addressed to Marcia J. Abbott; mabbott@chapman.edu

Received 28 April 2016; Revised 1 August 2016; Accepted 21 August 2016

Academic Editor: Aihua Zhang

Copyright (C) 2016 Shantaé M. Thornton et al. This is an open access article distributed under the Creative Commons Attribution License, which permits unrestricted use, distribution, and reproduction in any medium, provided the original work is properly cited.

Molecular mediators of metabolic processes, to increase energy expenditure, have become a focus for therapies of obesity. The discovery of cytokines secreted from the skeletal muscle (SKM), termed "myokines," has garnered attention due to their positive effects on metabolic processes. Interleukin-15 (IL-15) is a myokine that has numerous positive metabolic effects and is linked to the PPAR family of mitochondrial regulators. Here, we aimed to determine the importance of PPAR $\alpha$ and/or PPAR $\delta$ as targets of IL-15 signaling. C2C12 SKM cells were differentiated for 6 days and treated every other day with IL-15 (100 ng/mL), a PPAR $\alpha$ inhibitor (GW-6471), a PPAR $\delta$ inhibitor (GSK-3787), or both IL-15 and the inhibitors. IL-15 increased mitochondrial activity and induced PPAR $\alpha$, PPAR $\delta, \operatorname{PGC1} \alpha, \mathrm{PGC1} \beta, \mathrm{UCP} 2$, and Nrf1 expression. There was no effect of inhibiting PPAR $\alpha$, in combination with IL-15, on the aforementioned mRNA levels except for PGC1 $\beta$ and Nrfl. However, with PPAR $\delta$ inhibition, IL- 15 failed to induce the expression levels of PGC1 $\alpha$, PGC1 $\beta$, UCP2, and Nrf1. Further, inhibition of PPAR $\delta$ abolished IL-15 induced increases in citrate synthase activity, ATP production, and overall mitochondrial activity. IL-15 had no effects on mitochondrial biogenesis. Our data indicates that PPAR $\delta$ activity is required for the beneficial metabolic effects of IL-15 signaling in SKM.

\section{Introduction}

Obesity has become a modern epidemic and is growing in both prevalence and severity throughout the world. Obesity is one of the leading causes of preventable death, with more than one-third of all Americans considered overweight or obese [1, 2]. Current treatments for obesity include a calorie restricted diet and physical exercise, but sustaining long-term weight loss has proven to be a challenge for many [3]. A mainstay for treating obesity has been to increase metabolic rate, particularly through induction of mitochondrial activity in skeletal muscle (SKM). SKM is considered the largest organ in the body and acts to carry out bodily movement through generation of ATP, primarily via mitochondrial respiration [4].
Recently, SKM has attracted attention due to its newly identified ability to release cytokines, termed "myokines," into circulation that act to increase overall energy expenditure [5-9]. Many myokines (FGF-21, Irisin, BDNF5, interleukin-6, and interleukin-15, among others) increase in circulation following physical exercise, owing to their potential to reduce adiposity [9-11]. However, the downstream effectors of myokine signaling that positively influence metabolism remain elusive. In this regard, studies aimed at elucidating myokine signaling pathways, for the potential treatment and/or prevention of obesity, have come to the forefront of metabolic research.

Interleukin-15 (IL-15) is considered a myokine and is confirmed to increase mitochondrial activity, resulting in a decrease in overall adiposity [12-15]. Historically, IL-15 had 
been extensively studied as an activator of natural killer (NK) cells with antitumorigenic potential and anti-inflammatory properties $[11,16]$. Interestingly, in human and rodent studies, there is evidence that circulating levels of IL-15 increase following exercise, although this notion is somewhat controversial [17-21]. It is postulated that IL-15 acts to increase glucose uptake, fatty acid oxidation, and mitochondrial activity and lipolysis to reduce adiposity [14, 22-25]. Although the evidence is clear that IL-15 possesses positive metabolic effects, its direct downstream signaling pathways remain largely unknown. Many transcriptional regulators, responsible for inducing mitochondrial dynamics, have been linked to IL-15, such as peroxisome proliferator-activated receptors (PPARs), peroxisome proliferator-activated receptor gamma coactivator 1-alpha (PGC1 $\alpha)$, and silent mating type information regulation 2 homolog (SIRT1) [26-29].

PPARs are important transcriptional regulators linked to numerous beneficial metabolic effects, such as induction of mitochondrial biogenesis and fatty acid oxidation [30, 31]. Among the three isoforms, PPAR $\alpha$ is highly expressed in oxidative tissues, such as liver, heart, and type I SKM fibers, while PPAR $\delta$ appears to be ubiquitously expressed and acts to induce mitochondrial activity and lipid metabolism [30, 32, 33]. Both $\operatorname{PPAR} \alpha$ and $\delta$ have been suggested to promote induction of mitochondrial activity in many cell types and have garnered attention as potential antiobesogenic factors [30, 34-37]. PPAR $\gamma$ is most highly expressed in adipose tissue, both brown and white, and it plays an integral part in lipogenesis and adipogenesis [38]. The antidiabetic drug class, thiazolidinediones, acts to bind to and activate PPAR $\gamma$ to clear circulating lipids for the restoration of insulin sensitivity [39]. Much is known regarding the positive metabolic effects of PPARs but it is not known if myokines, such as IL-15, act to upregulate their transcriptional activity $[30,36]$. Interestingly, PPAR $\delta$ expression levels have been strongly linked to IL-15 signaling in SKM [26, 28]. However, the direct relationship between IL-15 and PPAR $\delta$ transcriptional activity, to modulate mitochondrial processes, has yet to be firmly established. On the other hand, there are reports that IL-15 acts to increase PPAR $\alpha$ expression levels in adipose tissue [29], but little is known regarding an IL-15-PPAR $\alpha$ relationship in SKM. Taken together, it is clear that a relationship between IL-15 and PPAR $\alpha$ and/or $\delta$ exits, but the depth of these relationships to induce metabolism, thereby, reducing adiposity is unknown.

Here we aimed to determine the necessity of PPAR $\alpha$ and/or $\delta$ as downstream mediators of the metabolically beneficial effects of IL-15 action on mitochondrial activity in SKM. Here, we show that $\operatorname{PPAR} \delta$ is required for IL-15 mediated induction of mitochondrial activity independent of PPAR $\alpha$ in SKM cells.

\section{Methods}

2.1. Reagents. $\mathrm{C} 2 \mathrm{C} 12$ cells were obtained from Sigma (\#91031101) along with Dulbecco's Modified Eagle Medium (DMEM; \#D6429), fetal bovine serum (FBS; \#F0926), horse serum (\#H1270), and insulin (\#I9278). Recombinant IL-15 was from GenScript (\#Z03309-50) and GW-6471 (\#11697) and GSK-3787 (\#15219) were obtained from Cayman Chemicals. Trizol (\#15596), SYBR green (\#A25742) and a SuperScript VILO reverse transcription kit (\#11754050) were purchased from ThermoFisher. The mitochondrial dye, Mito Red, was from Santa Cruz Biotechnology (SC-\#301164). Male C57BL6 mice were kept on a 12:12 light dark cycle and fed a standard diet and water ad libitum. Gastrocnemius muscle was obtained following euthanasia. All animal procedures were approved by the Institutional Animal Care and Use Committee at Chapman University.

2.2. C2C12 Cell Culture. The mouse immortalized SKM fibroblast cell line, $\mathrm{C} 2 \mathrm{C} 12$, was cultured in DMEM and supplemented with $10 \%$ FBS, $1 \%$ penicillin-streptomycin $(10,000 \mathrm{U} / \mathrm{mL})$, and $0.1 \%$ amphotericin B. When the cells reached $80 \%$ confluence, they were induced to differentiate into mature myotubes by supplementing the DMEM with $2 \%$ horse serum and $1 \mu \mathrm{M}$ insulin for 6 days. Myotube formation was confirmed by visualization using an inverted microscope. Upon induction of differentiation, cells were treated every other day, for 6 days, with either vehicle control (DMSO), IL15 (100 ng/mL), $10 \mu \mathrm{M}$ of a PPAR $\alpha$ inhibitor (GW-6471), $1 \mu \mathrm{M}$ of a PPAR $\delta$ inhibitor (GSK-3787), IL-15 + GW-6471, IL-15 + GSK-3787, or IL-15 + GW-6471 + GSK-3787.

2.3. Western Blotting. Western blotting was performed as previously described [40]. Briefly, C2C12 cells were lysed in a modified RIPA buffer supplemented with protease inhibitors (Pierce). Approximately $20 \mu \mathrm{g}$ of protein from the cell homogenate preparations was separated on a $4-12 \%$ gradient gel (GenScript) via SDS-PAGE. Proteins were transferred onto Immobilon-P polyvinylidene difluoride (PVDF) membranes and blocked with 5\% BSA in Tween-TBS for 1 hour. The membranes were then incubated $\left(4^{\circ} \mathrm{C}\right)$ in $5 \%$ BSA in Tween-TBS with antibodies $(1: 1000)$ against PPAR $\alpha$, $\operatorname{PPAR} \delta$, or GAPDH (Sigma). Following overnight incubation, the membranes were then probed with a secondary antibody (GenScript, 1:2000; or Thermo, 1:10,000). Blots were then washed and subjected to enhanced chemiluminescence (Pierce). Membranes were stripped in $0.5 \mathrm{M} \mathrm{NaOH}$ and probed for total proteins and subsequently GAPDH (Sigma) was used as a loading control.

2.4. RNA Extraction and Reverse Transcription. Standard RNA isolation procedures were performed on the cells following the 6-day treatment protocol, as previously described $[41,42]$. Mouse gastrocnemius muscle was used to verify IL-2 receptor expression. Briefly, cells or muscle tissue was lysed with Trizol reagent and chloroform was added to separate the RNA from the DNA and protein fractions. RNA was precipitated from the clear phase of the Trizol-chloroform mixture, followed by centrifugation at $12,000 \times \mathrm{g}$ at $4^{\circ} \mathrm{C}$, with isopropanol. The RNA pellet was washed with $75 \%$ ethanol and centrifuged at 7,500 $\times \mathrm{g}$ for 5 minutes, at $4^{\circ} \mathrm{C}$, and the pellets were air-dried. Using RNAse-free water, the pellets were resuspended and the RNA purity and concentration were quantified using a NanoDrop spectrophotometer. Reverse transcription of RNA to cDNA was performed on $2 \mu \mathrm{g}$ of RNA using SuperScript reverse transcriptase VILO kit. 
2.5. Mitochondrial DNA Assessments. Following the IL-15 treatment protocol, genomic DNA was isolated using a miniprep DNA isolation kit (Sigma). Briefly, $5 \times 10^{6}$ of cells in suspension, in lysis buffer, were mixed with RNase and proteinase $\mathrm{K}$ and incubated at $70^{\circ} \mathrm{C}$ for 10 minutes. Ethanol was added and then homogenates were transferred to the binding columns and subjected to a series of washes. The columns were air-dried and the DNA was eluted. DNA concentration and purity were assessed using a NanoDrop spectrophotometer (Thermo). Real time qPCR was carried out and a mitochondrial DNA marker was compared relative to a nuclear encoded marker (18S) and the corresponding sequences are displayed in Table 1.

2.6. Real Time Quantitative PCR. Real time $\mathrm{qPCR}$ was performed on the CDNA, using SYBR green in a 96-well plate. The primers are displayed in Table 1. GAPDH was used as an internal control and the ddCT method was used to calculate gene expression levels.

2.7. Live Cell Mitochondrial Activation Assay. Following the IL-15 treatment protocol, as described above, live cells were stained using a dye that becomes sequestered in active mitochondria [42]. The cells were then fixed with phosphate buffered formalin and DAPI was used as a nuclear stain. Fluorescence levels were assessed using an inverted Zeiss microscope and images were captured using an Axiovision camera. Relative and absolute fluorescence levels were calculated using Image J software. Measurements were corrected for total cell fluorescence to account for the variation in myotube size.

2.8. Citrate Synthase and ATP Assays. Citrate synthase (CS) activity was measured using a previously described protocol with some modifications [42-44]. To assess CS activity, C2C12 cell lysates were added to a 96-well plate containing $100 \mu \mathrm{M} \mathrm{5}, 5^{\prime}$-dithio-bis (2-nitrobenzoic acid) and $250 \mu \mathrm{M}$ acetyl-CoA. To initiate the reaction, $500 \mu \mathrm{M}$ oxaloacetate was added. The reaction was monitored in a microplate reader for 5 min at an ABS of 405. The specific activity was calculated as the absorbance rate per minute divided by the mercaptide extinction coefficient and expressed per $\mu \mathrm{g}$ of protein. ATP was measured on cell lysates using a fluorometric kit in a 96well plate (Sigma) and normalized to total protein.

2.9. Statistical Analysis. Data are presented as mean \pm SEM and all calculations were carried out using GraphPad Prism 6. A one-way ANOVA was calculated to determine multiple comparisons with a Fisher's post hoc analysis. For comparisons between two groups Student's $t$-test was performed. A $P$ level of 0.05 was used to determine statistical significance.

\section{Results}

3.1. IL-15 Induces Mitochondrial Activity in Skeletal Muscle Cells. To verify total mitochondrial activation via IL-15 signaling, a mitochondrial activity assay was performed to analyze relative mitochondrial activity in live SKM cells, as
TABLE 1: Primer sequences used for qPCR analysis.

\begin{tabular}{|c|c|}
\hline Gene & Sequence \\
\hline $\operatorname{PPAR} \alpha, \mathrm{F}$ & ATGGGGGTGATCGGAGGCTAATAG \\
\hline $\operatorname{PPAR} \alpha, \mathrm{R}$ & GGGTGGCAGGAAGGGAACAGAC \\
\hline $\operatorname{PPAR} \delta, \mathrm{F}$ & ACAAGGCCTCAGGGTACCA \\
\hline $\operatorname{PPAR} \delta, \mathrm{R}$ & GCCGAAAGAAGCCCTTACAG \\
\hline $\mathrm{PGC} 1 \alpha, \mathrm{F}$ & ACTGAGCTACCCTTGGGATG \\
\hline $\mathrm{PGCl} \alpha, \mathrm{R}$ & TAAGGATTTCGGTGGTGACA \\
\hline $\mathrm{PGCl} \beta, \mathrm{F}$ & TCCTGTAAAAGCCCGGAGTAT \\
\hline $\mathrm{PGCl} \beta, \mathrm{R}$ & GCTCTGGTAGGGGCAGTGA \\
\hline $\mathrm{UCP} 2, \mathrm{~F}$ & CCATTGCACGAGAGGAAGGGAT \\
\hline $\mathrm{UCP} 2, \mathrm{R}$ & GTCATGAGGTTGGCTTTCAGGAG \\
\hline Nrf1, F & TTGGAACAGCAGTGGCAAGA \\
\hline Nrf1, R & CTCACTTGCTGATGTATTTACTTCCAT \\
\hline $\mathrm{IL}-2 \mathrm{R} \gamma, \mathrm{F}$ & TACCAGACATTTGTTGTCCAGC \\
\hline $\mathrm{IL}-2 \mathrm{R} \gamma, \mathrm{R}$ & GCCCGTGGGATCACAAGATT \\
\hline Tfam, F & CAAGTCAGCTGATGGGTATGG \\
\hline Tfam, R & TTTCCCTGAGCCGAATCATCC \\
\hline nucDNA, F & TTGCGATAATTATAGTGGCT \\
\hline nucDNA, R & TACCTGGTTGATCCTGCCA \\
\hline mtDNA, F & GGCTTTGGAAACTGACTTGT \\
\hline mtDNA, R & TTGCGATAATTATAGTGGCT \\
\hline Cox $5 b, F$ & GGCGGAGAAGCCCTGAA \\
\hline Cox 5b, R & GCTGCATCTGTGAAGAGGACAAC \\
\hline Cox7al, F & CAGCTTGTAATGGGTTCCACAGT \\
\hline Cox7al, R & CAGCGTCATGGTCAGTCTGT \\
\hline Cox8b, F & AGAAAACCGTGTGGCAGAGA \\
\hline Cox $8 b, \mathrm{R}$ & GAACCATGAAGCCAACGACT \\
\hline Gapdh, F & AGGTCGGTGTGAACGGATTTG \\
\hline Gapdh, R & TGTAGACCATGTAGTTGAGGTCA \\
\hline
\end{tabular}

indicated by red staining (Figure 1(a)). According to quantification of the fluorescence signal, IL-15 stimulated mitochondrial activity by $44 \%$ in the SKM cells $(P<0.05$; Figure $1(\mathrm{~b}))$. IL-15 treatment stimulated increases in both PPAR $\alpha$ and PPAR $\delta$ protein expression levels (Figure 1(c)). To verify that the IL-15 receptor, IL-2R $\gamma$ [45], was present in the C2C12 cells mRNA levels in mouse gastrocnemius and $\mathrm{C} 2 \mathrm{C} 12$ cells were measured (Figure 1(d)). IL-15 induced mRNA expression levels of PPAR $\alpha$ (4-fold) and PPAR $\delta$ (2-fold), along with their cofactors PGCl $\alpha(100 \%)$ and PGCl $\beta(40 \%)$, when compared to control cells $(P<0.05$; Figure $2(\mathrm{a}))$. Owing to the capability of IL-15 to induce mitochondrial activity, the mitochondrial uncoupling protein-2 (UCP2) mRNA expression levels were increased by $50 \%(P<0.05$, Figure 2(b)). An additional factor associated with transcriptional activity of PPARs, nuclear respiratory factor 1 (Nrf1), and mRNA level was increased (30\%) with IL-15 treatment $(P<0.05$; Figure 2(b)). However, IL-15 failed to alter the expression levels of SIRT1 in the SKM cells $(P>0.05$; Figure 2(b)). In order to determine whether IL-15 stimulated increases in mitochondrial associated factors or activity was due to increased biogenesis, we assessed mtDNA and Tfam mRNA 


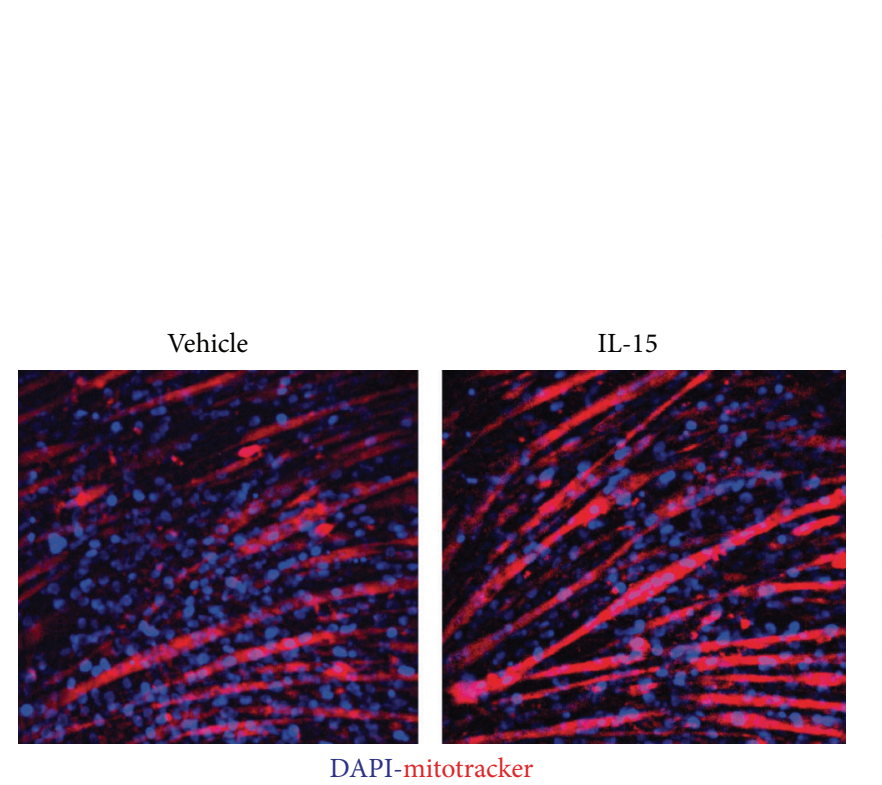

(a)

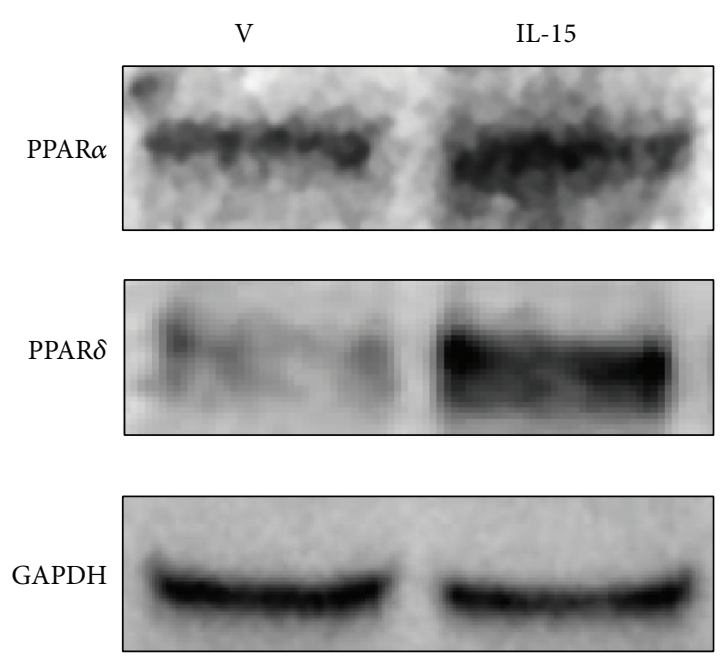

(c)

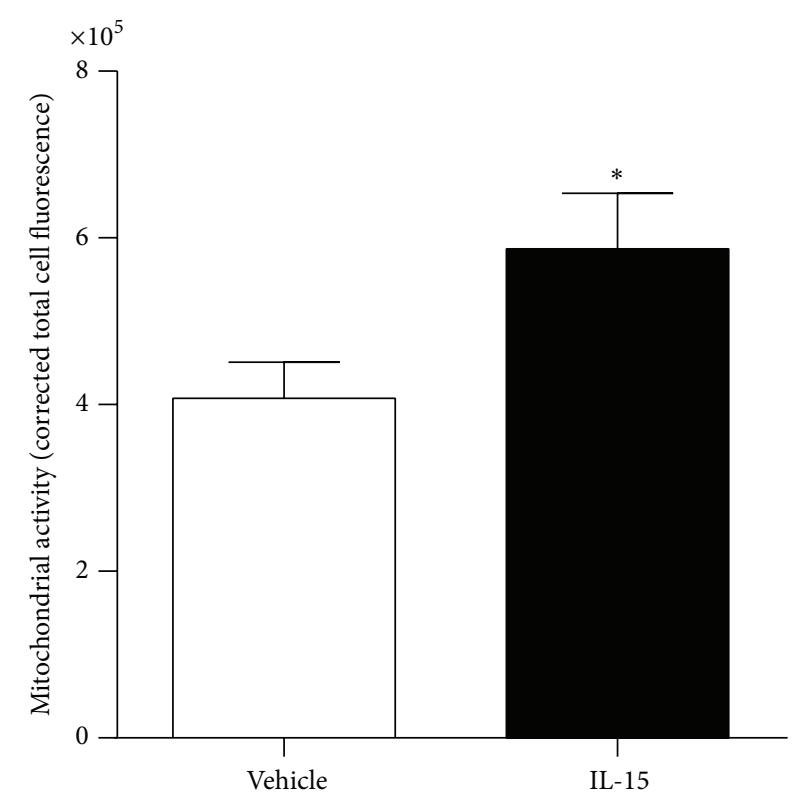

(b)

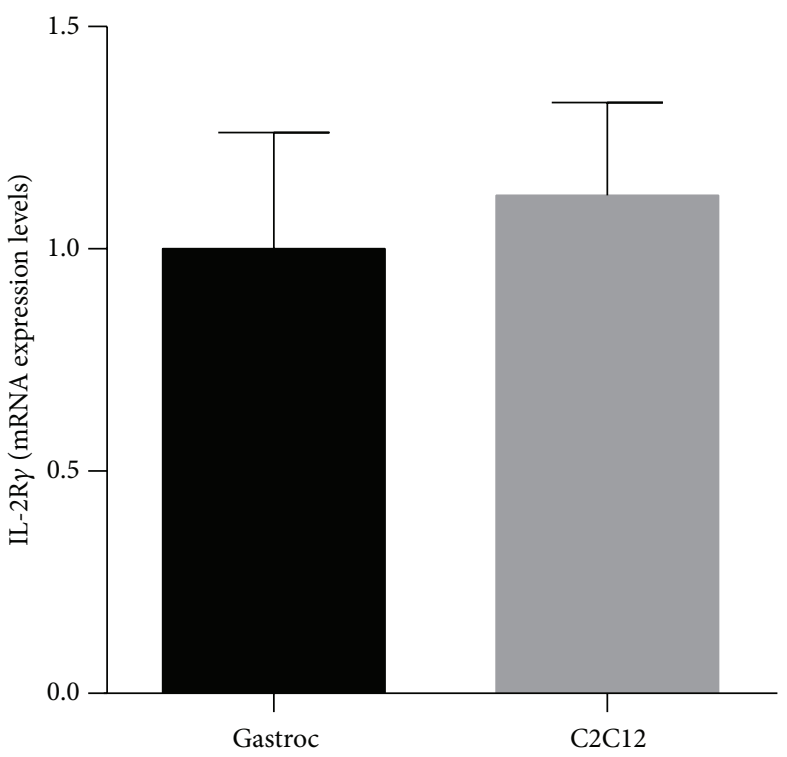

(d)

FIGURE 1: Effect of IL-15 signaling on mitochondrial activity. (a) Representative images of mitochondrial activity assessment in live cells using a fluorescent probe sequestered into active mitochondria; (b) quantifiable fluorescence corrected for myotube size; (c) western blot of $\operatorname{PPAR} \alpha$ and PPAR $\delta$ protein expression; (d) mRNA expression of IL-2R $\gamma$. Assessments were carried out on differentiated C2C12 myotubes following treatment with $100 \mathrm{ng} / \mathrm{mL}$ of IL-15 every other day for 6 days during the differentiation protocol. Image J was used to quantify cell fluorescence. GAPDH was used as control for protein and mRNA expression assessments. All values are displayed as mean \pm SEM, $n=3-6$ per group, ${ }^{*} P<0.05$.

expression levels. IL-15 had no effect on mtDNA content or on Tfam expression levels $(P>0.05$; Figures 3(a) and 3(b)).

3.2. The Involvement of PPARs in IL-15 Signaling. To verify the efficiency of the PPAR $\alpha$ inhibitor, GW, we confirmed a reduction in PPAR $\alpha$ mRNA expression levels by $57 \%$ when compared to vehicle control cells $(P<0.05$; Figure 4(a)). PPAR $\delta$ mRNA levels were assessed to determine the specificity of GW and there were no reductions with PPAR $\alpha$ inhibition $(P>0.05$; Figure 4(b)). Although PPAR $\alpha$ was inhibited, the stimulatory effects of IL-15 on PGCl $\alpha$ and UCP2 mRNA expression levels were maintained $(P<0.05$; Figure 4(c)). Conversely, the IL-15 induced increases in PGC1 $\beta$ and Nrf1 mRNA levels were abolished with PPAR $\alpha$ inhibition when compared to vehicle control cells $(P>0.05$; Figure $4(\mathrm{c}))$. Next, PPAR $\delta$ mRNA levels were confirmed 


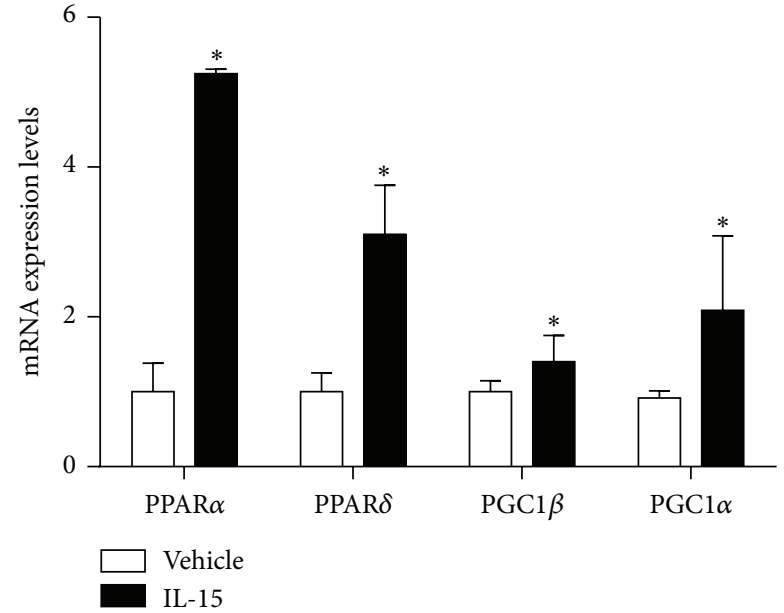

(a)

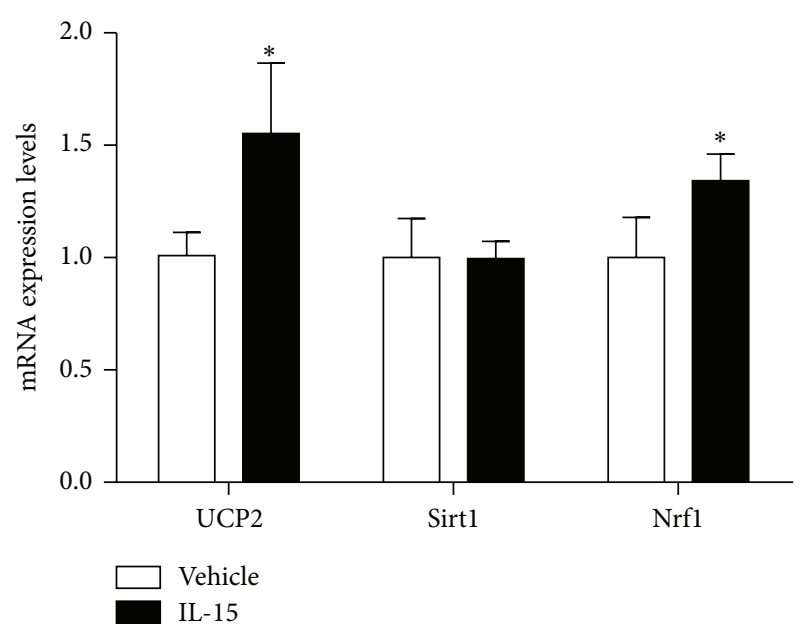

(b)

FIGURE 2: Effects of IL-15 signaling on mitochondrial associated factors. (a) mRNA expression of PPAR $\alpha$, PPAR $\delta$, PGC1 $\beta$, and PGCl $\alpha$; (b) mRNA expression of UCP2, SIRT1, and Nrf1. Assessments were carried out on differentiated C2C12 myotubes following treatment with $100 \mathrm{ng} / \mathrm{mL}$ of IL-15 every other day for 6 days during the differentiation protocol. GAPDH was used as an internal control for qPCR analysis. All values are displayed as means \pm SEM, $n=6-9$ per group, ${ }^{*} P<0.05$.

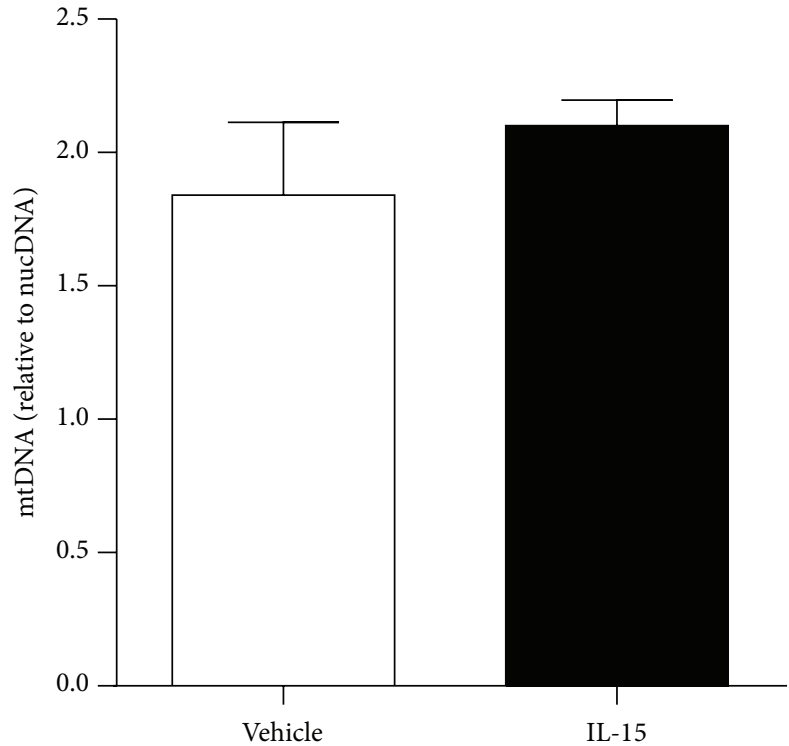

(a)

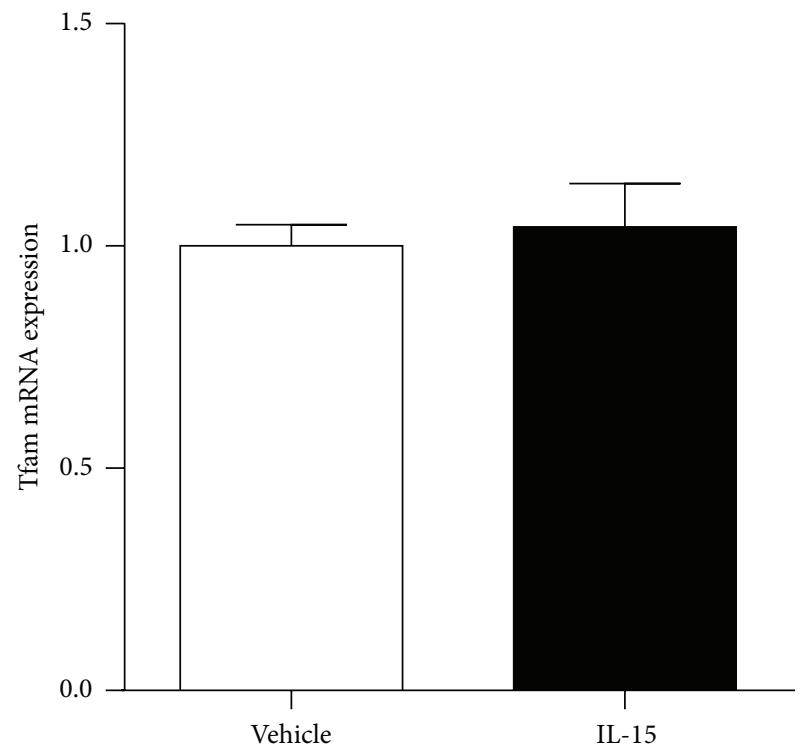

(b)

FIGURE 3: Effects of IL-15 signaling on mitochondrial biogenesis. (a) mitochondrial DNA (mtDNA) assessments; (b) mRNA expression of mitochondrial factor Tfam. Assessments were carried out on differentiated C2C12 myotubes following treatment with $100 \mathrm{ng} / \mathrm{mL}$ of IL-15 every other day for 6 days during the differentiation protocol. mtDNA was normalized to the total nuclearDNA (nucDNA) content. GAPDH was used as an internal control for qPCR analysis. All values are displayed as means \pm SEM, $n=6$.

to be reduced by $60 \%$, when compared to vehicle control cells, with its inhibitor (GSK) $(P<0.05$; Figure 5(a)). Conversely the PPAR $\delta$ inhibitor had no effects on PPAR $\alpha$ mRNA levels, confirming the specificity of GSK $(P>0.05$; Figure 5(b)). Unlike the PPAR $\alpha$ experiments, inhibition of $\operatorname{PPAR} \delta$ signaling resulted in a loss of IL-15 induced increases in $\mathrm{PGCl} \alpha, \mathrm{PGC1} \beta, \mathrm{UCP} 2$, and $\mathrm{Nrf1}$ when compared to vehicle control cells $(P>0.05$, Figure 5(c)).

3.3. PPARS Is Required for IL-15 Mediated Increases in Mitochondrial Activity. In the SKM cells, IL-15 stimulated increases in CS activity by $43 \%$, when compared to vehicle 


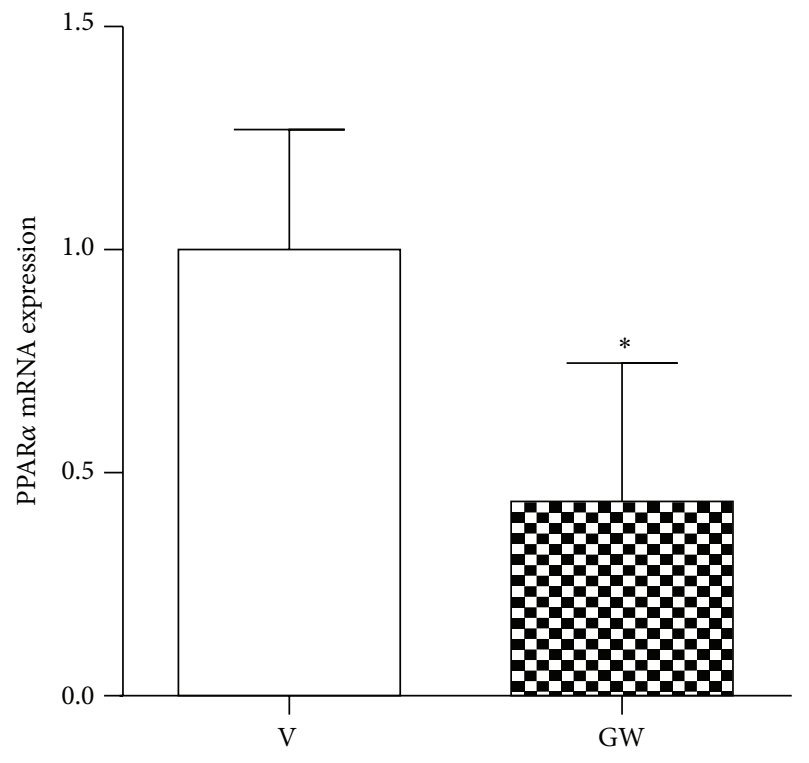

(a)

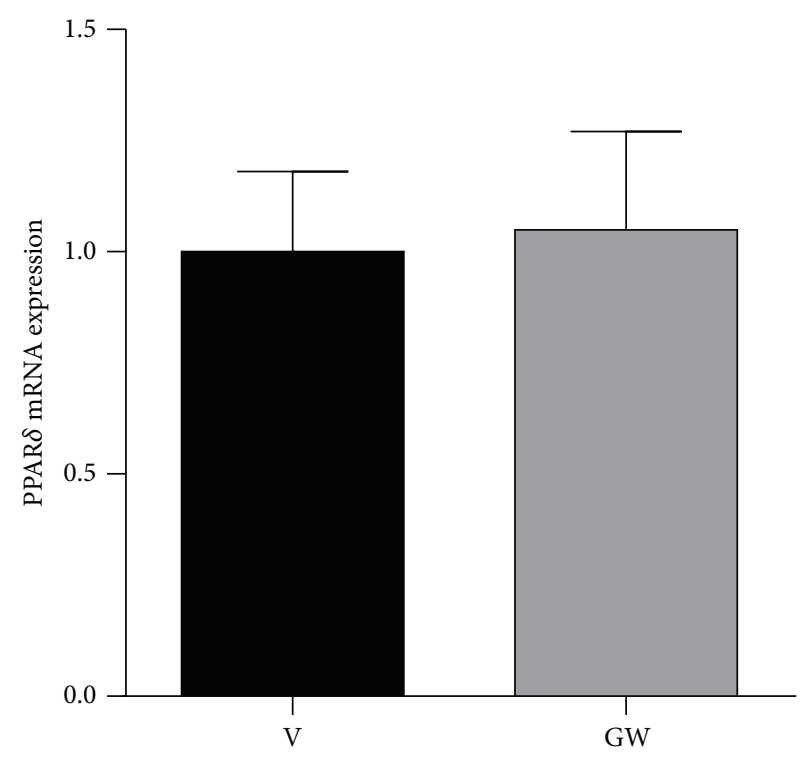

(b)

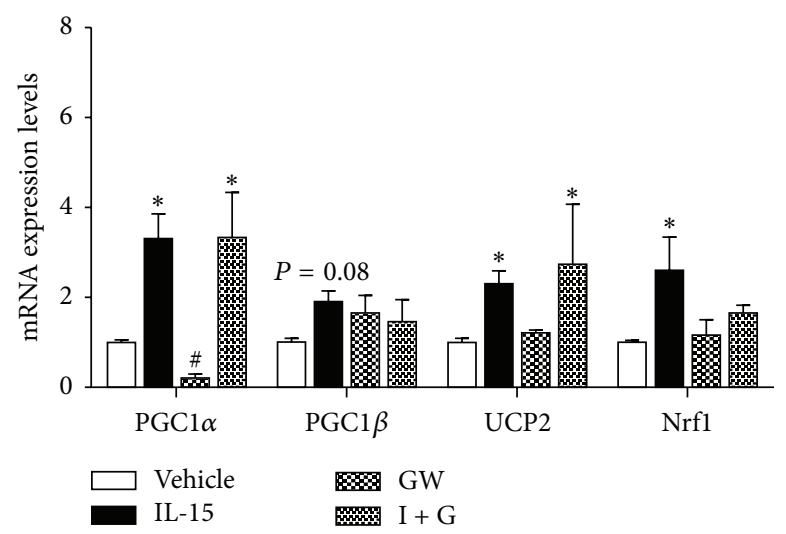

(c)

FIGURE 4: Effects of PPAR $\alpha$ inhibition on IL-15 mediated alterations of mitochondrial associated factors. (a) mRNA expression of PPAR $\alpha$ following inhibition with GW-6471 (GW); (b) mRNA expression of PPAR $\delta$ following exposure to GW; (c) mRNA expression of PGCl $\alpha$, PGC1 $\beta$, UCP2, and Nrf1 with IL-15 treatment in combination with GW. Throughout differentiation, cells were treated every other day, for 6 days, with either vehicle control (DMSO), IL-15 (100 ng/mL), $10 \mu \mathrm{M}$ of the PPAR $\alpha$ inhibitor (GW-6471), or IL-15 + GW-6471 (I + G). GAPDH was used as an internal control for qPCR analysis. All values are displayed as means \pm SEM, $n=6-9$ per group, ${ }^{*}$ different from vehicle and GW groups; ${ }^{*}$ different from all groups; $P<0.05$.

cells, $(P<0.05)$ and these stimulatory effects were eliminated with PPAR $\delta$ inhibition $(P>0.05$; Figure 6(a)). Likewise, ATP content was elevated (30\%) with IL-15 treatment and PPAR $\delta$ inhibition abolished these effects $(P<0.05$; Figure 6(b)). IL15 induced increases in mRNA levels of cytochrome $C$ oxidase (Cox) isoforms 5b, 7al, and $8 \mathrm{~b}$ were dependent on PPAR $\delta$ activity $(P<0.05$; Figure $6(\mathrm{c}))$. Mitochondrial activity was assessed directly in live SKM cells and the IL-15 induced increases in mitochondrial activity remained elevated (53\%), when compared to vehicle control cells, with PPAR $\alpha$ inhibition $(P<0.05$; Figures $7(\mathrm{a})$ and $7(\mathrm{~b}))$. However, inhibition of PPAR $\delta$ prevented the effects of IL-15 induced increases in mitochondrial activity $(P>0.05$; Figures $7(\mathrm{a})$ and $7(\mathrm{~b}))$. To further solidify the PPAR $\delta$-dependent-PPAR $\alpha$-independent IL-15 mediated signaling, mitochondrial activity was abolished with IL-15 stimulation in the presence of both PPAR $\alpha$ and $\operatorname{PPAR} \delta$ inhibitors $(P>0.05$; Figures $7(\mathrm{a})$ and $7(\mathrm{~b}))$.

\section{Discussion}

Data from this study solidify the notion that IL-15 is directly involved in mediating mitochondrial activity in SKM cells. Importantly, our data indicate that $\operatorname{PPAR} \delta$ activation is required for IL-15 signaling to carry out its stimulatory effects on mitochondrial activity. Further, based on our findings, we have ruled out PPAR $\alpha$ as a potential modulator 


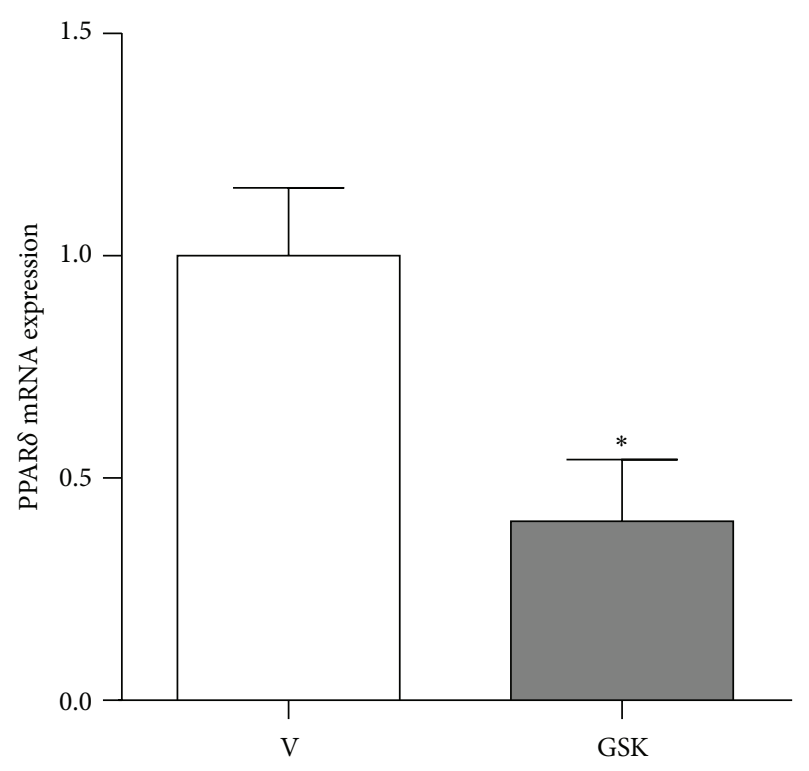

(a)

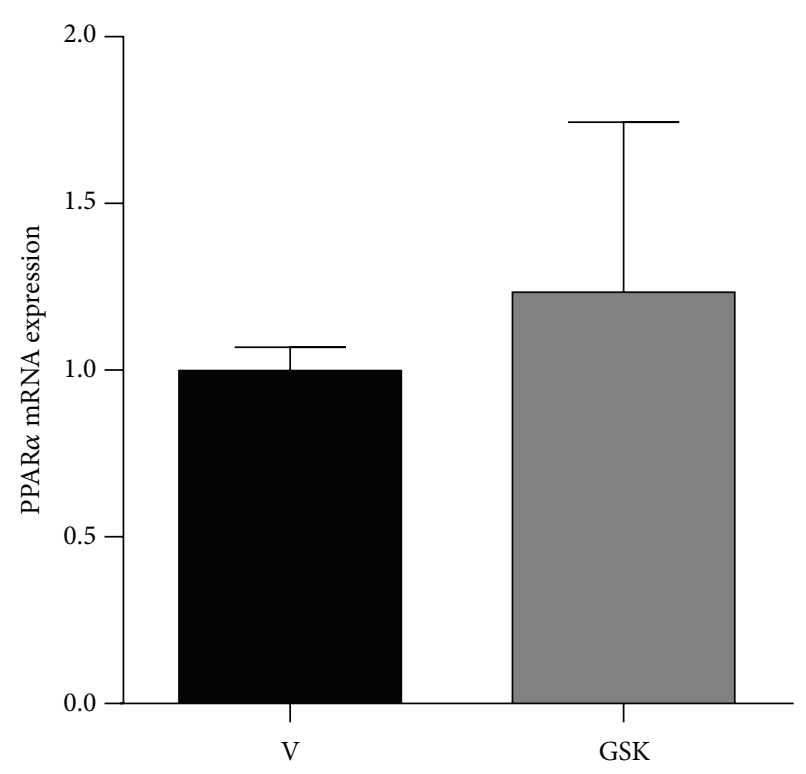

(b)

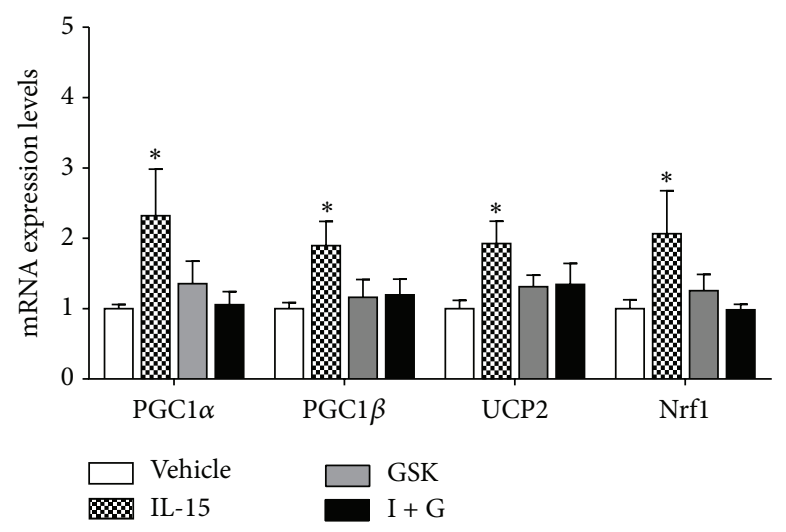

(c)

FIGURE 5: Effects of PPAR $\delta$ inhibition on IL-15 mediated alterations of mitochondrial associated factors. (a) mRNA expression of PPAR $\delta$ following inhibition with GSK-3787 (GSK); (b) mRNA expression of PPAR $\alpha$ following exposure to GSK; (c) mRNA expression of PGCl $\alpha$, PGC1 $\beta$, UCP2, and Nrf1 with IL-15 treatment in combination with GSK. Throughout differentiation, cells were treated every other day, for 6 days, with either vehicle control (DMSO), IL-15 (100 ng/mL), $1 \mu \mathrm{M}$ of the PPAR $\delta$ inhibitor (GSK-3787), or IL-15 + GSK-3787 (I + G). GAPDH was used as an internal control for qPCR analysis. All values are displayed as means \pm SEM, $n=6-9$ per group, ${ }^{*}$ different from all groups; $P<0.05$

of IL-15 induced mitochondrial activity. However, we have evidence for a role of an IL-15-PPAR $\alpha$ signaling relationship in mediating PGCl $\beta$ and Nrfl expression levels. Altogether it is clear that PPAR $\delta$ is required for IL-15 induced expression of mitochondrial regulators and activity in SKM cells.

In line with other reports in adipose tissue [25], treatment with IL-15 increased mitochondrial associated processes in SKM cells, as indicated by increased activity of CS and ATP production. Our data confirm other reports showing that IL15 has the ability to induce activity of the key Krebs Cycle factor, CS, in SKM from mice [25]. It has been postulated that one route that IL-15 acts to reduce adiposity is through its ability to increase lipolysis and mitochondrial activity in adipocytes [25]. Additionally, IL-15 has been shown to increase the activity of mitochondrial processes, such as fatty acid oxidation $[24,46]$. Here we show, for the first time, that IL-15 acts to directly increase overall mitochondrial activity in live SKM cells. On the other hand, it does not appear that IL15 induces increases in mitochondrial biogenesis as indicated by the mtDNA and Tfam assessments in the $\mathrm{C} 2 \mathrm{C} 12$ cells. Likewise, in the current study, activity of CS, ATP production, and Cox isoform expression were fully dependent on PPAR $\delta$ activity with IL-15 stimulation in the SKM cells. Further, it has previously been established that IL-15 increases expression levels of key factors that function to increase mitochondrial activity and biogenesis in both white and brown adipose tissue as well as in SKM [22, 26, 27, 29, 47]. Our results are in line with those findings, as PPAR $\alpha$, PPAR $\delta$ PGCl $\alpha$, 


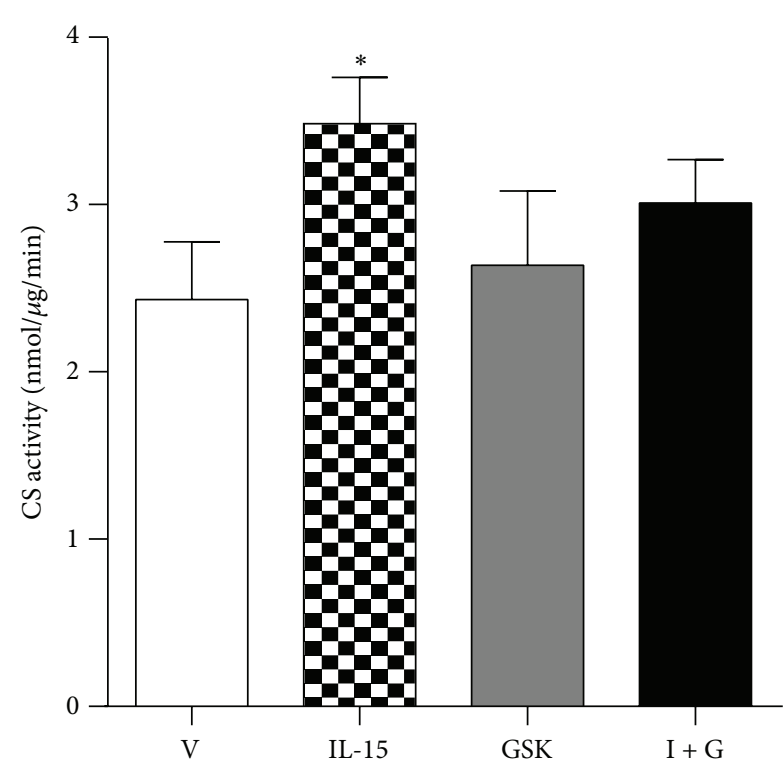

(a)

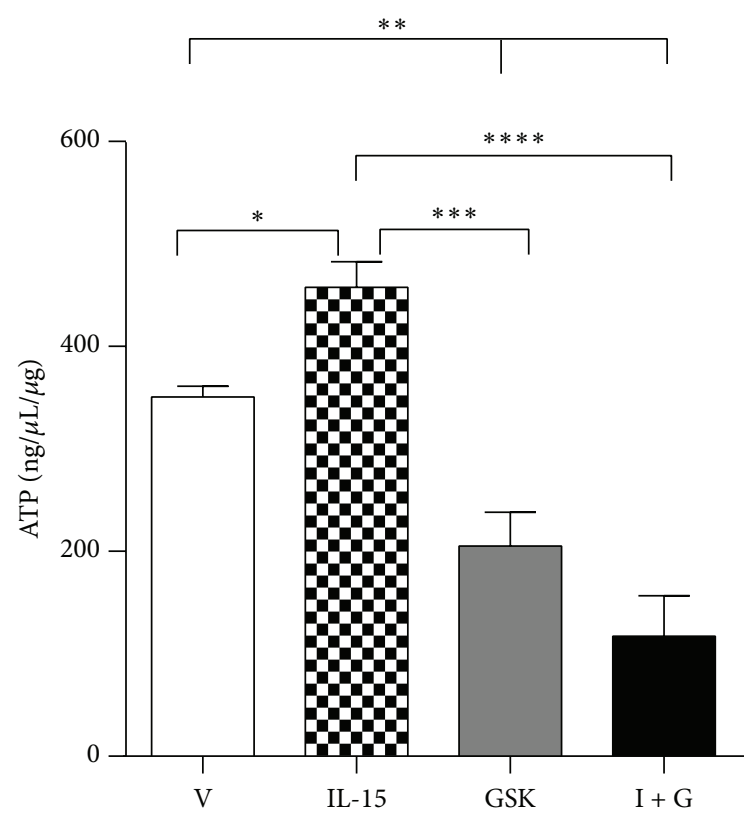

(b)

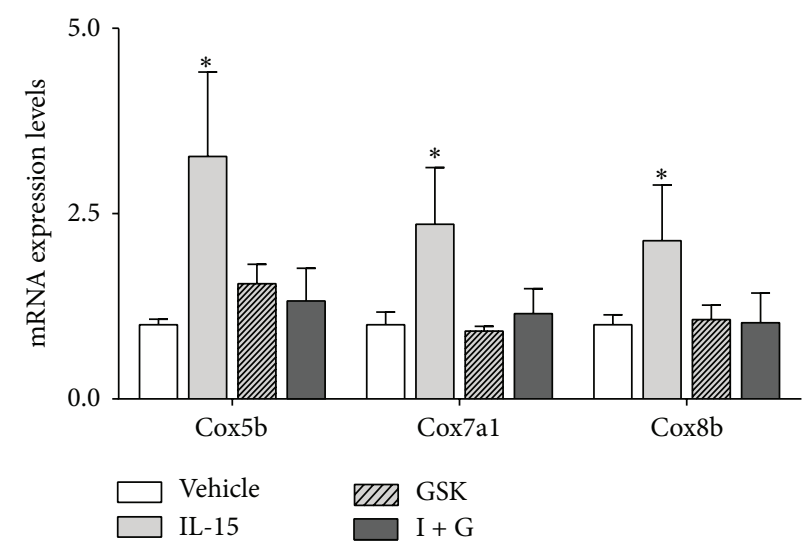

(c)

FIgURE 6: Involvement of PPAR $\delta$ in IL-15 mediated mitochondrial activity. (a) Citrate synthase (CS) activity; (b) total intracellular ATP content; (c) mRNA expression of cytochrome C oxidase isoforms Cox5b, Cox7al, and Cox8b. Assessments were carried out on total cell lysates from C2C12 SKM cells following treatment every other day, for 6 days, with either vehicle control (DMSO), IL-15 (100 ng/mL), $1 \mu \mathrm{M}$ of the PPAR $\delta$ inhibitor (GSK-3787), or IL-15 + GSK-3787 (I + G). All values are displayed as means \pm SEM, $n=6$ per group, ${ }^{*}$ different from vehicle control group; $P<0.05 ;{ }^{* *}$ different from all groups, $P<0.01 ;{ }^{* * *}$ different from IL-15 group, $P<0.001 ;{ }^{* * * *}$ GSK different from IL-15 group, $P<0.001$.

PGC1 $\beta$, UCP2, and Nrf1 expression levels were all elevated with IL-15 stimulation. Conversely, our data do not support the notion that IL-15 stimulates mitochondrial biogenesis, which is in agreement with previously reported data in mouse SKM [48]. Unlike other studies, our treatment with IL-15 failed to increase SIRT1 expression levels $[27,28]$. Here we employed an in vitro model to study the effects of IL-15 on SKM cells and the other reports linking IL-15 to SIRT1 were carried out in a transgenic mouse model overexpressing IL-15 $[27,28]$. Therefore, it is a possibility that IL-15 induced SIRT1 expression levels are secondary to direct activation of the IL15 signaling pathway in SKM. On the other hand, it cannot be ruled out that SIRT1 activity is regulated by IL-15, as we have only assessed mRNA expression levels. Taken together, it is clear that PPAR $\delta$ is required for the IL-15 induced effects on mitochondrial associated factors and activity.

Here, our data point to a strong link between IL-15 and PPAR $\delta$ in SKM cells, but PPAR $\alpha$ activity involvement had not been fully assessed in SKM [24, 26-28]. PPAR $\alpha$ has been associated with IL-15 signaling in adipose tissue and, with this in mind, we attempted to elucidate a potential IL-15$\operatorname{PPAR} \alpha$ relationship in C2C12 cells [29]. Interestingly, IL-15 induced PPAR $\alpha$ expression levels nearly 4-fold, while PPAR $\delta$ expression was induced only 2 -fold, suggesting that PPAR $\alpha$ may be a more direct target of IL-15 signaling. However, with inhibition of PPAR $\alpha, \operatorname{PGC} 1 \alpha$ and UCP2 mRNA expression 


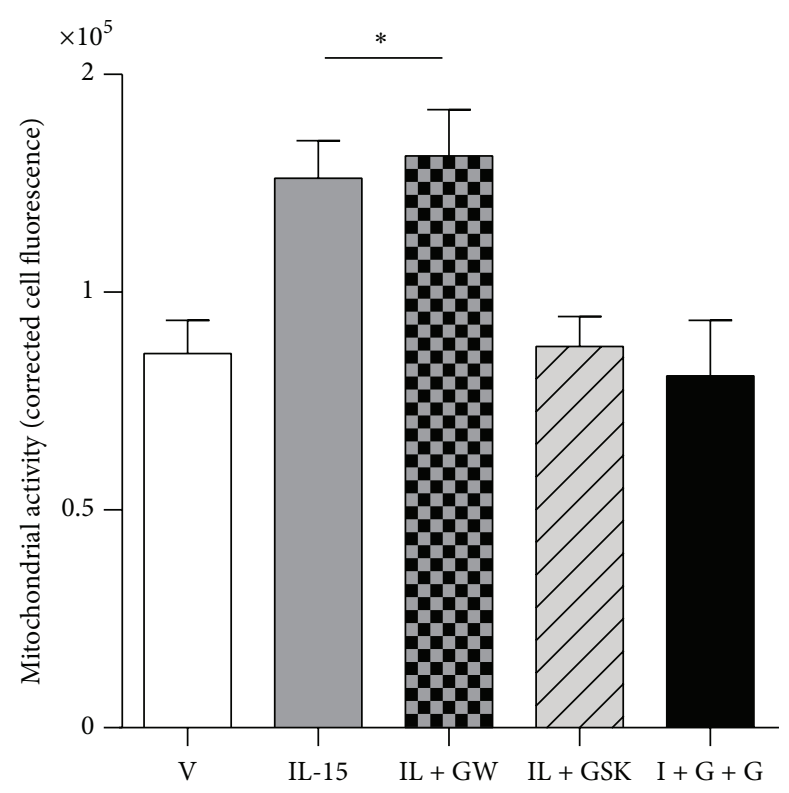

(a)
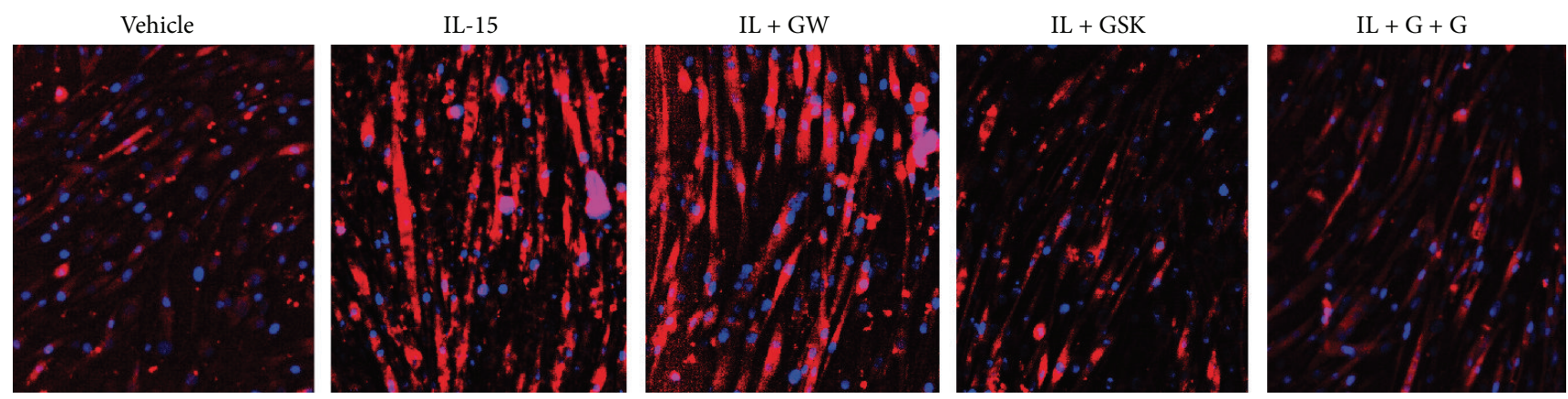

DAPI-mitotracker

(b)

FIGURE 7: Involvement of PPAR $\alpha$ and PPAR $\delta$ in IL-15 mediated mitochondrial activity in live cells. (a) Quantifiable fluorescence corrected for myotube size. Assessments were carried out on differentiated C2C12 myotubes following treatment with vehicle control (DMSO), IL-15 (100 ng/mL), IL-15 + GW-6471 (I + GW), IL-15 + GSK-3787 (I + GSK), and IL-15 + GW + GSK (I + G + G) every other day for 6 days during the differentiation protocol. (b) Representative images of mitochondrial activity assessment in live cells using a fluorescent probe sequestered into active mitochondria; Image J was used to quantify cell fluorescence. All values are displayed as means \pm SEM, $n=6$ per group, ${ }^{*}$ different from all groups; $P<0.05$.

levels were maintained with IL-15 treatment. Conversely, Nrf1 mRNA expression levels were equivocal to the vehicle control cells with IL-15 treatment when PPAR $\alpha$ was inhibited. Nrf1 has been shown to be directly regulated by PPAR $\alpha$, with a greater affinity than PPAR $\delta$, which may explain the reduction in its expression levels with IL-15 treatment and PPAR $\alpha$ inhibition [49]. Furthermore, PGC1 $\beta$ expression levels were not statistically different from vehicle control cells with both IL-15 and PPAR $\alpha$ inhibitor. On the other hand, with PPAR $\alpha$ inhibition, the stimulatory effect of IL-15 on mitochondrial activity was maintained. Although we show a potential connection between IL-15-PPAR $\alpha$ mediated increases in some mitochondrial associated factors, these relationships do not appear to translate to functional assays, such as mitochondrial activity. It should be noted that addition of the vehicle control (DMSO) in the inhibitor studies yielded alterations in baseline mRNA expression levels when compared to mRNA levels in the absence of DMSO. Further, our data is dependent on pharmacological inhibitors of PPARs. Genetic knockdown studies would provide additional support for our data. However, the functionality of IL-15 induced increases in mitochondrial activity is relevant in mature fully differentiated SKM cells. Therefore, methodological constraints do not allow for genetic knockdown studies on fully differentiated cells with repeated treatments.

Even though our data indicate that PPAR $\alpha$ activity is not required for IL-15 mediated mitochondrial activity in SKM cells, we definitively show that PPAR $\delta$ activity is a requirement. Indeed, the master mitochondrial regulators, PGCl $\alpha$ and PGCl $\beta$, mRNA expression levels were both 
reduced with PPAR $\delta$ inhibition in combination with IL-15 stimulation. Both PGC1 $\alpha$ and $\mathrm{PGCl} \beta$ are responsible for the numerous beneficial effects of exercise on mitochondrial processes and biogenesis and signal in concert with PPARs $[50,51]$. Additionally, PGC1 $\alpha$ is responsible for regulating mitochondrial uncoupling, via UCP2, and our data are in support of this pathway, as indicated by the reductions of UCP2 expression with inhibition of PPAR $\delta$ with IL-15 treatment [52]. The importance of IL-15 induced PPAR $\delta$ activation for the regulation of mitochondrial activity is further supported by the reduction of Nrf1 mRNA expression levels with PPAR $\delta$ inhibition and IL-15 treatment. In this regard, not only does IL-15 signal directly through PPAR $\delta$ but also its effects initiate a master metabolic regulation pathway, including UCP2 and Nrf1 as downstream targets.

\section{Conclusions}

It is widely accepted that PPARs play an important role in mediating mitochondrial processes to prevent and/or treat metabolic disorders $[30,32,34,53,54]$. We provide evidence for the requirement of $\operatorname{PPAR} \delta$ as a direct target of IL15 signaling to carry out mitochondrial processes in SKM. Additionally, our data indicate that PPAR $\alpha$ is not necessary for the beneficial effects of IL-15 signaling on mitochondrial activation in SKM. Although we have shown the importance of PPAR $\delta$ in IL-15 signaling, the signals directly downstream the IL-2 receptor remain unknown in SKM. Therefore, examining the effects of IL-15 on IL-2R targets such as Akt and the Jak/STAT pathway is required in SKM. In order to define the complex relationship of IL-15 signaling and PPARs further in vivo studies are warranted. Overall, understanding the players involved in IL-15 signaling will give rise to potential therapies for obesity and its associated disorders.

\section{Competing Interests}

The authors declare that there are no competing interests regarding the publication of this paper.

\section{Acknowledgments}

The authors would like to thank Dr. LeBris Quinn for providing intellectual input and Ty Nakamoto and Brady Slater for their technical assistance. Research reported in this publication was supported by the American College of Sports Medicine Research Endowment and Chapman University Faculty Development Awards.

\section{References}

[1] C. L. Ogden, M. D. Carroll, B. K. Kit, and K. M. Flegal, "Prevalence of childhood and adult obesity in the United States, 2011-2012," The Journal of the American Medical Association, vol. 311, no. 8, pp. 806-814, 2014.

[2] CDC and NCHS, Underlying Cause of Death 1999-2013, CDC Wonder Online Database, 2015.
[3] B. Egan and J. R. Zierath, "Exercise metabolism and the molecular regulation of skeletal muscle adaptation," Cell Metabolism, vol. 17, no. 2, pp. 162-184, 2013.

[4] R. T. Hepple, "Mitochondrial involvement and impact in aging skeletal muscle," Frontiers in Aging Neuroscience, vol. 6, article 211, 2014.

[5] A.-S. Arnold, A. Egger, and C. Handschin, "PGC- $1 \alpha$ and myokines in the aging muscle-a mini-review," Gerontology, vol. 57, no. 1, pp. 37-43, 2010.

[6] K. Walsh, "Adipokines, Myokines and Cardiovascular Disease," Circulation Journal, vol. 73, no. 1, pp. 13-18, 2009.

[7] K. Eckardt, S. W. Görgens, S. Raschke, and J. Eckel, "Myokines in insulin resistance and type 2 diabetes," Diabetologia, vol. 57, no. 6, pp. 1087-1099, 2014.

[8] S. Raschke and J. Eckel, "Adipo-Myokines: two sides of the same coin-mediators of inflammation and mediators of exercise," Mediators of Inflammation, vol. 2013, Article ID 320724, 16 pages, 2013.

[9] B. K. Pedersen, "Muscle as a secretory organ," in Comprehensive Physiology, John Wiley \& Sons, New York, NY, USA, 2013.

[10] B. K. Pedersen and M. A. Febbraio, "Muscles, exercise and obesity: skeletal muscle as a secretory organ," Nature Reviews Endocrinology, vol. 8, no. 8, pp. 457-465, 2012.

[11] C. T. Lutz and L. S. Quinn, "Sarcopenia, obesity, and natural killer cell immune senescence in aging: altered cytokine levels as a common mechanism," Aging, vol. 4, no. 8, pp. 535-546, 2012.

[12] J. M. Argilés, F. J. López-Soriano, and S. Busquets, “Therapeutic potential of interleukin-15: a myokine involved in muscle wasting and adiposity," Drug Discovery Today, vol. 14, no. 3-4, pp. 208-213, 2009.

[13] B. Alvarez, N. Carbó, J. López-Soriano et al., "Effects of interleukin-15 (IL-15) on adipose tissue mass in rodent obesity models: evidence for direct IL-15 action on adipose tissue," Biochimica et Biophysica Acta-General Subjects, vol. 1570, no. 1, pp. 33-37, 2002.

[14] H. Sun and D. Liu, "Hydrodynamic delivery of interleukin 15 gene promotes resistance to high fat diet-induced obesity, fatty liver and improves glucose homeostasis," Gene Therapy, vol. 22, no. 4, pp. 341-347, 2015.

[15] L. S. Quinn and B. G. Anderson, "Interleukin-15, IL-15 receptoralpha, and obesity: concordance of laboratory animal and human genetic studies," Journal of Obesity, vol. 2011, Article ID 456347, 8 pages, 2011.

[16] E. F. Castillo and K. S. Schluns, "Regulating the immune system via IL-15 transpresentation," Cytokine, vol. 59, no. 3, pp. 479490, 2012.

[17] S. R. Gray and T. Kamolrat, "The effect of exercise induced cytokines on insulin stimulated glucose transport in $\mathrm{C} 2 \mathrm{C} 12$ cells," Cytokine, vol. 55, no. 2, pp. 221-228, 2011.

[18] A. Rinnov, C. Yfanti, S. Nielsen et al., "Endurance training enhances skeletal muscle interleukin-15 in human male subjects," Endocrine, vol. 45, no. 2, pp. 271-278, 2014.

[19] J. D. Crane, L. G. Macneil, J. S. Lally et al., "Exercise-stimulated interleukin-15 is controlled by AMPK and regulates skin metabolism and aging," Aging Cell, vol. 14, no. 4, pp. 625-634, 2015.

[20] M. Catoire, M. Mensink, E. Kalkhoven, P. Schrauwen, and S. Kersten, "Identification of human exercise-induced myokines using secretome analysis," Physiological Genomics, vol. 46, no. 7, pp. 256-267, 2014. 
[21] J. R. Pierce, J. M. Maples, and R. C. Hickner, "Il-15 concentrations in skeletal muscle and subcutaneous adipose tissue in lean and obese humans: local effects of IL-15 on adipose tissue lipolysis," American Journal of Physiology-Endocrinology and Metabolism, vol. 308, no. 12, pp. E1131-E1139, 2015.

[22] S. Busquets, M. Figueras, V. Almendro, F. J. López-Soriano, and J. M. Argilés, "Interleukin-15 increases glucose uptake in skeletal muscle. An antidiabetogenic effect of the cytokine," Biochimica et Biophysica Acta-General Subjects, vol. 1760, no. 11, pp. 16131617, 2006.

[23] K. M. Ajuwon and M. E. Spurlock, "Direct regulation of lipolysis by interleukin-15 in primary pig adipocytes," American Journal of Physiology-Regulatory Integrative and Comparative Physiology, vol. 287, no. 3, pp. R608-R611, 2004.

[24] V. Almendro, S. Busquets, E. Ametller et al., "Effects of interleukin-15 on lipid oxidation. Disposal of an oral [14C]triolein load," Biochimica et Biophysica Acta-Molecular and Cell Biology of Lipids, vol. 1761, no. 1, pp. 37-42, 2006.

[25] N. G. Barra, R. Palanivel, E. Denou et al., "Interleukin-15 modulates adipose tissue by altering mitochondrial mass and activity," PLoS ONE, vol. 9, no. 12, Article ID el14799, 2014.

[26] G. C. O'Connell and E. E. Pistilli, "Interleukin-15 directly stimulates pro-oxidative gene expression in skeletal muscle invitro via a mechanism that requires interleukin-15 receptor alpha," Biochemical and Biophysical Research Communications, vol. 458, no. 3, pp. 614-619, 2015.

[27] L. S. Quinn, B. G. Anderson, J. D. Conner, T. Wolden-Hanson, and T. J. Marcell, "IL-15 is required for postexercise induction of the pro-oxidative mediators PPAR $\delta$ and SIRT1 in male mice," Endocrinology, vol. 155, no. 1, pp. 143-155, 2014.

[28] L. S. Quinn, B. G. Anderson, J. D. Conner, and T. WoldenHanson, "IL-15 overexpression promotes endurance, oxidative energy metabolism, and muscle PPAR $\delta$ SIRT1, PGC- $1 \alpha$ and PGC-1 $\beta$ expression in male mice," Endocrinology, vol. 154, no. 1, pp. 232-245, 2013.

[29] V. Almendro, G. Fuster, S. Busquets et al., "Effects of IL-15 on rat brown adipose tissue: uncoupling proteins and PPARs," Obesity, vol. 16, no. 2, pp. 285-289, 2008.

[30] W. Fan and R. Evans, "PPARs and ERRs: molecular mediators of mitochondrial metabolism," Current Opinion in Cell Biology, vol. 33, pp. 49-54, 2015.

[31] J. Perez-Schindler and A. Philp, "Regulation of skeletal muscle mitochondrial function by nuclear receptors: implications for health and disease," Clinical Science, vol. 129, no. 7, pp. 589-599, 2016.

[32] G. D. Barish, V. A. Narkar, and R. M. Evans, "PPAR $\delta$ : a dagger in the heart of the metabolic syndrome," The Journal of Clinical Investigation, vol. 116, no. 3, pp. 590-597, 2006.

[33] Y.-X. Wang, C.-H. Lee, S. Tiep et al., "Peroxisome-proliferatoractivated receptor $\delta$ activates fat metabolism to prevent obesity," Cell, vol. 113, no. 2, pp. 159-170, 2003.

[34] K.-D. Wagner and N. Wagner, "Peroxisome proliferatoractivated receptor beta/delta $(\operatorname{PPAR} \beta / \delta)$ acts as regulator of metabolism linked to multiple cellular functions," Pharmacology and Therapeutics, vol. 125, no. 3, pp. 423-435, 2010.

[35] Y.-X. Wang, C.-L. Zhang, R. T. Yu et al., "Regulation of muscle fiber type and running endurance by PPAR $\delta$," PLoS Biology, vol. 2, no. 10, article e294, 2004.

[36] L. L. C. Poulsen, M. Siersbæk, and S. Mandrup, "PPARs: fatty acid sensors controlling metabolism," Seminars in Cell and Developmental Biology, vol. 23, no. 6, pp. 631-639, 2012.
[37] A.-M. Krogsdam, C. A. F. Nielsen, S. Neve et al., "Nuclear receptor corepressor-dependent repression of peroxisomeproliferator-activated receptor $\delta$-mediated transactivation," Biochemical Journal, vol. 363, part 1, pp. 157-165, 2002.

[38] C. Janani and B. D. Ranjitha Kumari, "PPAR gamma gene-a review," Diabetes and Metabolic Syndrome: Clinical Research and Reviews, vol. 9, no. 1, pp. 46-50, 2015.

[39] J. M. Lehmann, L. B. Moore, T. A. Smith-Oliver, W. O. Wilkison, T. M. Willson, and S. A. Kliewer, "An antidiabetic thiazolidinedione is a high affinity ligand for peroxisome proliferatoractivated receptor $\gamma$ (PPAR $\gamma$ )," The Journal of Biological Chemistry, vol. 270, no. 22, pp. 12953-12956, 1995.

[40] M. J. Abbott, A. M. Edelman, and L. P. Turcotte, "CaMKK is an upstream signal of AMP-activated protein kinase in regulation of substrate metabolism in contracting skeletal muscle," American Journal of Physiology-Regulatory Integrative and Comparative Physiology, vol. 297, no. 6, pp. R1724-R1732, 2009.

[41] L. Wattanachanya, W.-D. Lu, R. K. Kundu et al., "Increased bone mass in mice lacking the adipokine apelin," Endocrinology, vol. 154, no. 6, pp. 2069-2080, 2013.

[42] T. Tang, M. J. Abbott, M. Ahmadian, A. B. Lopes, Y. Wang, and H. S. Sul, "Desnutrin/ATGL activates PPAR $\delta$ to promote mitochondrial function for insulin secretion in islet $\beta$ cells," Cell Metabolism, vol. 18, no. 6, pp. 883-895, 2013.

[43] M. J. Abbott, L. D. Bogachus, and L. P. Turcotte, "AMPK $\alpha 2$ deficiency uncovers time dependency in the regulation of contraction-induced palmitate and glucose uptake in mouse muscle," Journal of Applied Physiology, vol. 111, no. 1, pp. 125134, 2011.

[44] M. J. Abbott and L. P. Turcotte, "AMPK- $\alpha 2$ is involved in exercise training-induced adaptations in insulinstimulated metabolism in skeletal muscle following high-fat diet," Journal of Applied Physiology, vol. 117, no. 8, pp. 869-879, 2014.

[45] J. G. Giri, S. Kumaki, M. Ahdieh et al., "Identification and cloning of a novel IL-15 binding protein that is structurally related to the $\alpha$ chain of the IL-2 receptor," The EMBO Journal, vol. 14, no. 15, pp. 3654-3663, 1995.

[46] E. Dozio, A. E. Malavazos, E. Vianello et al., "Interleukin-15 and soluble interleukin- 15 receptor $\alpha$ in coronary artery disease patients: association with epicardial fat and indices of adipose tissue distribution," PLoS ONE, vol. 9, no. 3, article e90960, 2014.

[47] L. S. Quinn, B. G. Anderson, L. Strait-Bodey, A. M. Stroud, and J. M. Argilés, "Oversecretion of interleukin-15 from skeletal muscle reduces adiposity," American Journal of PhysiologyEndocrinology and Metabolism, vol. 296, no. 1, pp. E191-E202, 2008.

[48] L. S. Quinn, B. G. Anderson, J. D. Conner, and T. WoldenHanson, "IL-15 overexpression promotes endurance, oxidative energy metabolism, and muscle PPAR $\delta$ SIRT1, PGC- $1 \alpha$ and PGC-1 $\beta$ expression in male mice," Endocrinology, vol. 154, no. 1, pp. 232-245, 2013.

[49] K. Baar, "Involvement of PPAR $\gamma$ co-activator-1, nuclear respiratory factors 1 and 2, and PPAR $\alpha$ in the adaptive response to endurance exercise," Proceedings of the Nutrition Society, vol. 63, no. 2, pp. 269-273, 2004.

[50] D. M. Muoio and T. R. Koves, "Skeletal muscle adaptation to fatty acid depends on coordinated actions of the PPARs and PGCl $\alpha$ : implications for metabolic disease," Applied Physiology, Nutrition and Metabolism, vol. 32, no. 5, pp. 874-883, 2007. 
[51] C. Handschin and B. M. Spiegelman, "Peroxisome proliferatoractivated receptor $\gamma$ coactivator 1 coactivators, energy homeostasis, and metabolism," Endocrine Reviews, vol. 27, no. 7, pp. 728-735, 2006.

[52] T. Nakatani, N. Tsuboyama-Kasaoka, M. Takahashi, S. Miura, and O. Ezaki, "Mechanism for peroxisome proliferatoractivated receptor- $\alpha$ activator-induced up-regulation of UCP2 mRNA in rodent hepatocytes," Journal of Biological Chemistry, vol. 277, no. 11, pp. 9562-9569, 2002.

[53] S. J. Bensinger and P. Tontonoz, "Integration of metabolism and inflammation by lipid-activated nuclear receptors," Nature, vol. 454, no. 7203, pp. 470-477, 2008.

[54] R. K. Semple, V. K. K. Chatterjee, and S. O'Rahilly, "PPAR $\gamma$ and human metabolic disease," The Journal of Clinical Investigation, vol. 116, no. 3, pp. 581-589, 2006. 


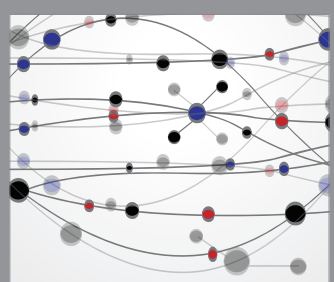

The Scientific World Journal
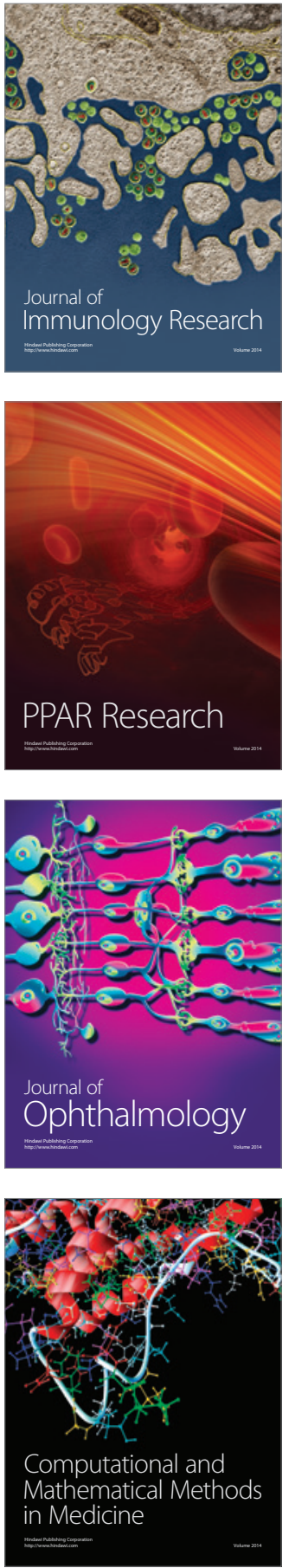

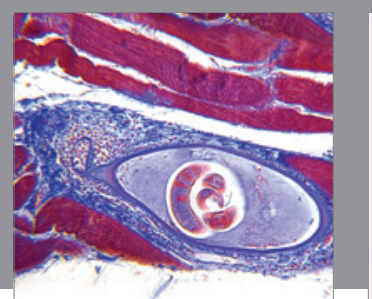

Gastroenterology Research and Practice

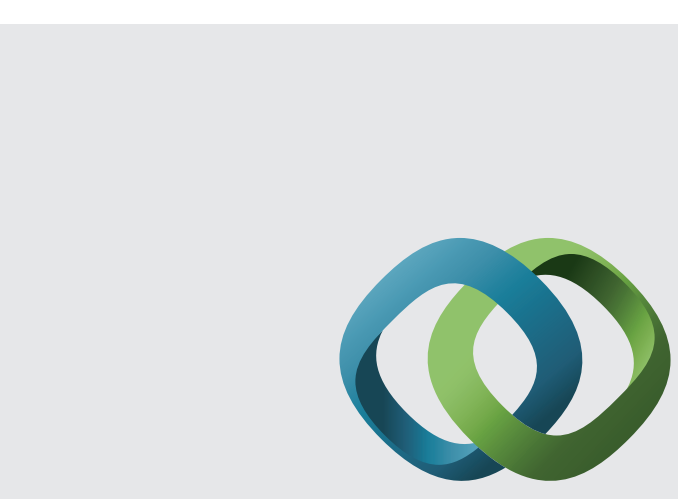

\section{Hindawi}

Submit your manuscripts at

http://www.hindawi.com
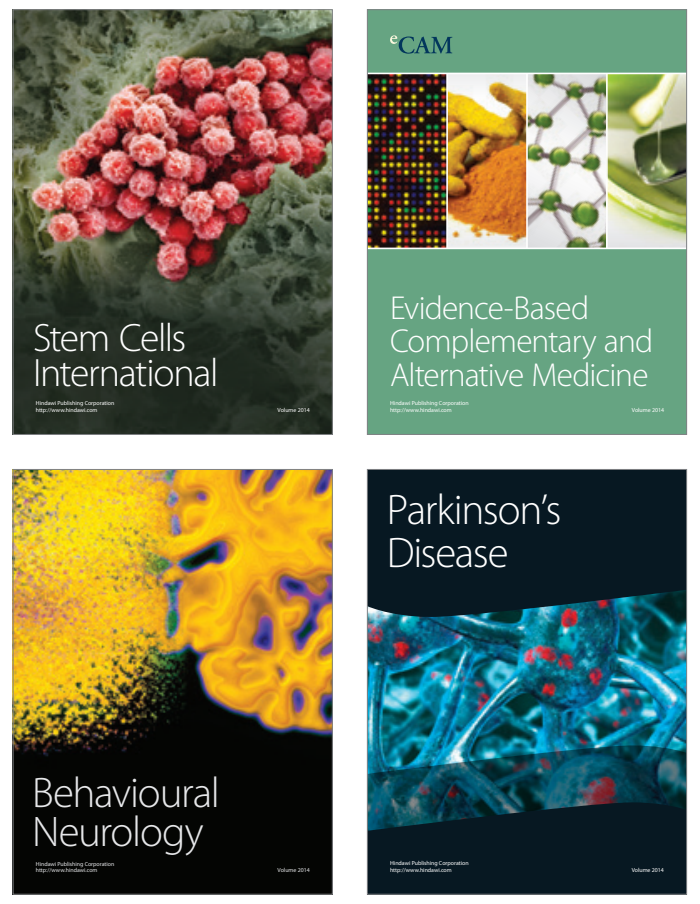
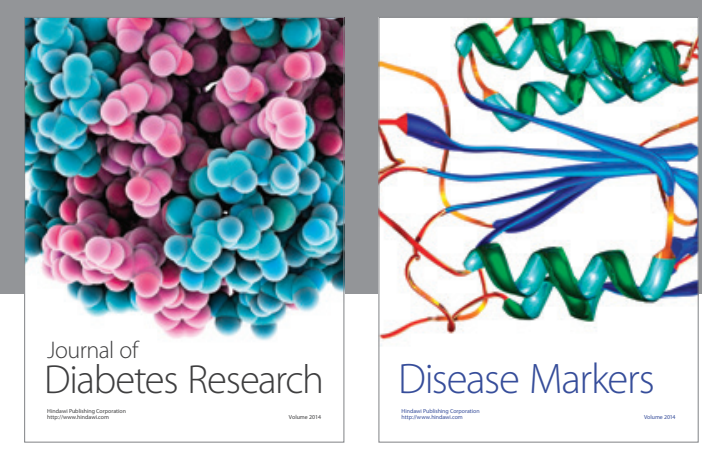

Disease Markers
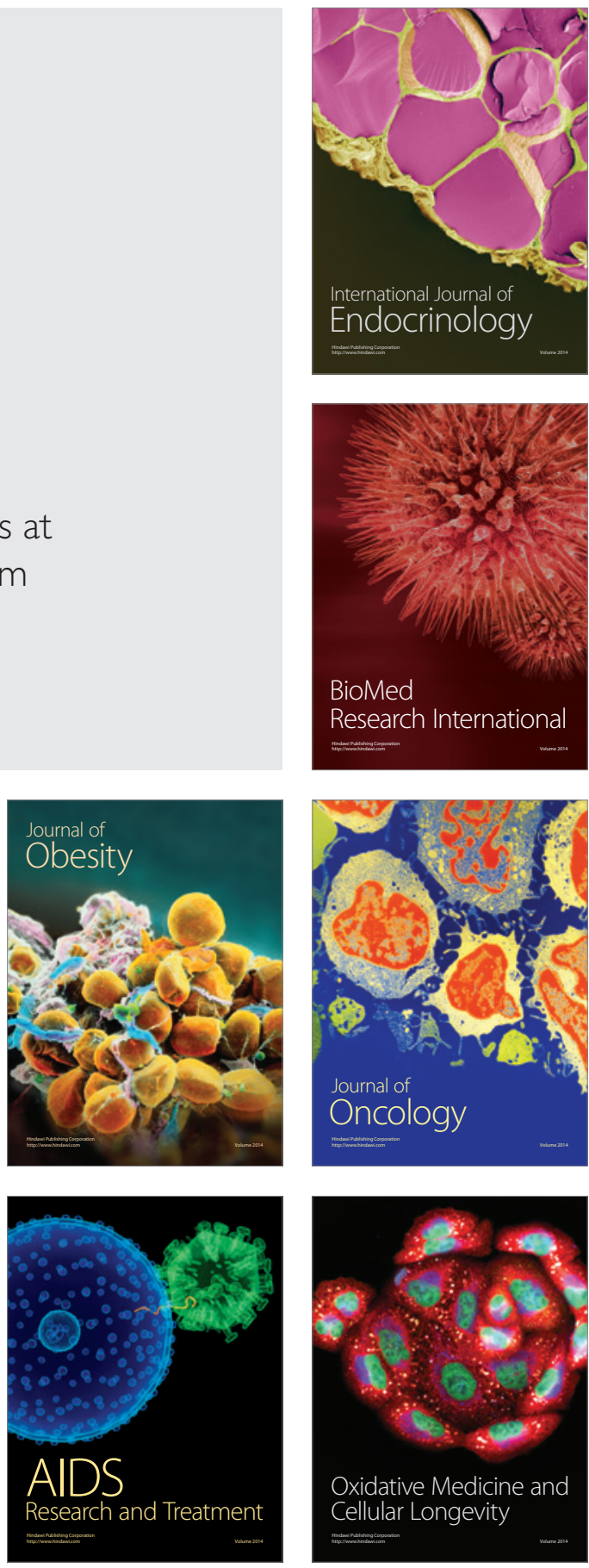